\title{
ANALISIS NILAI TAMBAH DAN EFISIENSI USAHA PENGOLAHAN JERUK SIAM PONTIANAK (Citrus nobilis var. microcarpa) GABUNGAN KELOMPOK TANI SUMBER ANUGERAH DESA SEGEDONG KECAMATAN TEBAS KABUPATEN SAMBAS
}

\author{
Wilis Widi Wilujeng ${ }^{*}$, Erlinda Yurisinthae ${ }^{1}$, Iwan Sasli ${ }^{1}$ \\ *Mahasiswa MMA Fakultas Pertanian Universitas Tanjungpura Pontianak \\ ${ }^{1}$ Dosen Fakultas Pertanian Universitas TanjungPura
}

\begin{abstract}
Objectives of this research was to analyzed the added value and business efficiency of processing of Siam Pontianak citrus in farmer group Sumber Anugerah. This research was conducted in Tebas sub-distric because this area was the center of citrus producer. Farmer group of Sumber Anugerah was choosen because the first place of citrus processing in to juice was occur here. Parameters used consist : costs of main ingredient, costs of supporting material, depreciaton costs and labors costs. There was two analytical techniques used : added value analysis and efficiency with Cobb-Douglas test. Results of the research was : 1) Bussines of citrus Processing that used main and supporting ingredients, depreciation cost and labors have no added value as much as -Rp 675. 2) The use of main and supporting ingredients, costs of labours in this bussines was not efficient yet, with coefficient of efficiency was $-50,09$. Further more, to get added values needs to increase selling price of the juice. Efficiency will fulfill if the capacity of each process increase and the continuity of process maintain.
\end{abstract}

Keywords : added value, citrus, efficiency, juice, processing

\section{PENDAHULUAN}

Departemen Pertanian Republik Indonesia tahun 2005 telah menetapkan 17 komoditas yang menjadi prioritas pembangunan pertanian selama lima tahun (tahun 20052010) yaitu: padi, jagung, kedelai, kelapa, cengkeh, tanaman obat, pisang, jeruk, bawang merah, angrek, sapi, kambing dan domba, unggas, kelapa sawit, karet dan kakao. Komoditas kelapa sawit, karet dan kakao merupakan mandat dari Lembaga Riset Perkebunan Indonesia (LRPI). Dari 14 komoditas yang menjadi mandat prioritas Puslitbang/Balai Besar yang berada di bawah Badan Litbang Pertanian, teridentifikasi tujuh komoditas yang memiliki prospek untuk dikembangkan agroindustrinya yaitu: padi, jagung, kelapa, cengkeh, pisang, jeruk dan hasil ternak.

Kabupaten Sambas merupakan salah satu kabupaten di Kalimantan Barat, dengan luas wilayah $6.394,70 \mathrm{~km}^{2}$ (4,36 persen total luasan provinsi) merupakan wilayah yang terletak pada bagian pantai barat paling utara dari wilayah Propinsi Kalimantan Barat. Tanaman andalan Kabupaten Sambas adalah jeruk siam. Lebih dari 90 persen produksi jeruk siam di Kalimantan Barat berasal dari Kabupaten Sambas (BPS Kalbar, 2008). Produksi jeruk siam merupakan yang terbesar dibanding produksi jenis buah-buahan lain, yakni sebesar 89,52 persen. Produksi jeruk siam ini sebesar 145.534,4 ton. Produk buah andalan lain adalah rambutan dan durian, masing-masing sebesar $4.124,70$ ton dan 714,1 ton. Selain buah Jeruk, Rambutan dan Durian, Kabupaten Sambas juga terdapat buah Pisang dan Duku yang tingkat produksinya masing-masing sebesar 4.902,7 ton dan 82,7 ton. Sebenarnya jeruk ini bukanlah hasil produksi pertanian Kota Pontianak. Sentra tanaman jeruk justru berasal dari Kecamatan Tebas, Kabupaten Sambas. Data dari Dinas Pertanian Kabupaten Sambas menunjukkan produksi jeruk terbanyak berada di Kecamatan Tebas sebesar 
34.571,70 ton. Jeruk asal Kabupaten Sambas ini dinamakan varietas Jeruk Siam Pontianak (Citrus nobilis var. microcarpa). Hal ini sesuai dengan SK Menteri Pertanian RI nomor 466/Kpts/PD.210/9/2003 tanggal 15 September 2003.

Selain untuk menambah nilai jual jeruk, pengolahan lanjutan juga berperan dalam membuat produk lebih spesifik dalam menghadapi persaingan bebas. Persaingan global tingkat nasional mau tidak mau harus dihadapi, dimana daerah sentra produksi jeruk tidak lagi hanya Kalimantan Barat, melainkan Sulawesi Selatan dan Jawa Timur juga memacu pengembangan jeruk siam mereka. Jadi, selain harus adanya kespesifikan atau kekhasan jeruk siam pontianak baik rasa, grading dan packing, pengolahan lanjutan perlu dikembangkan.

Strategi pembangunan pertanian pada periode sebelumnya lebih banyak diarahkan pada usaha meningkatkan produksi pertanian. Upaya peningkatan produktivitas dan produksi pertanian belum menunjukkan keberhasilan pembangunan pertanian seutuhnya, terutama dalam peningkatan kualitas hidup petani. Peningkatan produktivitas belum menjamin terjadinya peningkatan kesejahteraan petani, selama petani hanya mampu menjual hasil panennya dalam bentuk bahan mentah. Pemasaran hasil dalam bentuk bahan mentah, memiliki beberapa kelemahan diantaranya: tidak adanya nilai tambah, mudah rusak, daya simpan terbatas, dan konsistensi mutu sulit dijamin. Melihat dari sifat hasil panen yang rentan ini, maka hendaknya hasil pertanian diolah lebih lanjut agar dapat memberikan nilai insentif yang lebih besar kepada petani, yang pada gilirannya akan dapat meningkatkan pendapatan petani.

Usaha pengolahan minuman jeruk ini memiliki prospek yang sangat besar mengingat dari ketersediaan bahan baku. Pengolahan lanjutan juga akan berpengaruh pada saat panen raya, karena pada saat tersebut harga buah jeruk mengalami penurunan. Sesuai dengan teori ekonomi, jika permintaan terhadap suatu produk lebih sedikit dari penawaran, maka harga produk akan menurun. Jika permintaan terhadap buah jeruk segar stabil, tetapi penawaran terhadap buah ini meningkat maka otomatis akan terjadi over demand. Maka untuk menyiasati hal tersebut, pengolahan lanjutan jeruk merupakan salah satu cara agar tidak terjadi penurunan harga.

Berdasarkan latar belakang diatas maka yang dijadikan pokok permasalahan dalam penelitian ini adalah a. Berapa besar nilai tambah usaha pengolahan Jeruk Siam Pontianak yang dilakukan oleh Gapoktan Sumber Anugerah, b. Sudah efisienkah usaha pengolahan Jeruk Siam Pontianak yang dilakukan oleh Gapoktan Sumber Anugerah.

\section{METODE PENELITIAN}

Penelitian ini dilaksanakan di Desa Segedong Kecamatan Sambas Kabupaten Sambas. Tepatnya pada rumah produksi Jeruk Siam Pontianak yang dikelola oleh Gapoktan Sumber Anugerah. Lokasi penelitian ditentukan secara sengaja (purposive). Dasar dari pemilihan daerah penelitian ini adalah bahwa Gapoktan ini berada di Kecamatan Tebas yang merupakan sentra produksi Jeruk Siam Pontianak.

Jenis data yang dikumpulkan adalah data primer dan data sekunder. Data yang digunakan berupa data selama satu tahun, yaitu tahun 2010. Digunakan data produksi tahun 2010 karena pada tahun tersebut tersedia datanya. Data primer dikumpulkan melalui wawancara. Wawancara dengan pengelola rumah produksi, dan observasi yaitu dengan mengamati secara langsung objek penelitian.

Metode analisis data yang digunakan adalah analisis kuantitatif. Analisis yang 
digunakan meliputi analisis nilai tambah dan analisis efisiensi usaha pengolahan jus jeruk.

\section{Analisis Nilai Tambah}

Besarnya nilai tambah karena proses pengolahan didapat dari pengurangan harga barang jadi yang dihasilkan dengan biaya pengolahan bahan baku. Usaha pengolahan minuman kemasan jeruk ini memiliki nilai tambah jika terdapat peningkatan nilai dari bahan baku buah jeruk segar menjadi minuman kemasan.

Suatu usaha pengolahan dikatakan memiliki nilai tambah jika harga barang jadi lebih besar nilainya dari biaya produksi. Dengan demikian kriteria pengambilan keputusan dari nilai tambah adalah :

$>$ jika nilai tambah $(\mathrm{a}-\mathrm{b})>0$, maka usaha pengolahan tersebut memiliki nilai tambah

$>$ jika $a-b \leq 0$, maka usaha pengolahan tersebut tidak memiliki nilai tambah

\section{Analisis Efisiensi Minuman Kemasan Jeruk Siam Pontianak}

Menurut Soekartawi (2003) fungsi Cobb Douglas digunakan untuk mengetahui pengaruh penggunaan faktor produksi. Bentuk umum fungsi produksi Cobb-Douglas adalah:

$$
Q=\delta . I^{\alpha}
$$

Keterangan:

$\mathbf{Q}=$ Output

I =Jenis input yang digunakan dalam proses produksi dan dipertimbangkan untuk dikaji

$\boldsymbol{\delta}=$ indeks efisiensi penggunaan input dalam menghasilkan output

$\boldsymbol{\alpha}=$ elastisitas produksi dari input yang digunakan.

Bentuk Fungsi Produksi Cobb Douglas pada usaha pengolahan jus jeruk :

$$
Q=\delta .\left(I_{1}^{\alpha 1} I_{2}{ }^{\alpha 2} I_{3}{ }^{\alpha 3} I_{4}^{\alpha 4}\right)
$$

Ket :

$\mathbf{Q}=$ Output (Kemasan)

$\mathbf{I}_{\mathbf{1}}=$ Jumlah bahan baku( Kilogram)

$\mathbf{I}_{\mathbf{2}}$ = Biaya Penyusutan (Rupiah)

$\mathbf{I}_{\mathbf{3}}=$ Jumlah Bahan Penunjang (Rupiah)

$\mathbf{I}_{\mathbf{4}}=$ Jumlah Tenaga Kerja (HOK)

$\delta=$ indeks efisiensi penggunaan input dalam menghasilkan output

$\boldsymbol{\alpha}=$ elastisitas produksi dari input yang digunakan.

Indeks efisiensi akan didapat dari perhitungan, dengan semakin tinggi indeks efisiensi produksi berarti usaha pengolahan jeruk Citrus Van Sambas menjadi semakin efisien. Kriteria pengambilan keputusan :

$>$ jika $\delta \leq 1$, maka usaha pengolahan tidak efisien

$>$ jika $\delta>1$, maka usaha pengolahan sudah efisien 


\section{HASIL DAN PEMBAHASAN}

Kecamatan Tebas dengan luas sebesar $394,97 \mathrm{~km}^{2}$ atau sekitar 6,19 persen dari luas wilayah Kabupaten Sambas. Kecamatan Tebas terdiri dari 23 Desa. Desa terluas adalah Desa Maribas dengan luas $87,50 \mathrm{~km}^{2}$ atau 22,12 persen dari luas Kecamatan Tebas, sedangkan untuk desa terkecil adalah Desa Tebas Kuala dengan luas 3,83 $\mathrm{km}^{2}$, atau 0,97 persen dari luas Kecamatan Tebas.

Gapoktan Sumber Anugerah dibentuk berdasarkan kesepakatan Kontak Tani Nelayan se-Desa Segedong Kecamatan Tebas Kabupaten Sambas tanggal 9 Oktober 2006 di Citrus Center. Pengukuhan gapoktan ini dilakukan oleh Camat Tebas pada tanggal 18 Oktober 2006 dengan Surat Pernyataan Pengukuhan Gabungan Kelompok Tani Sumber Anugerah Nomor: 441.55/295/PP/X/2006. Sejak awal pendirian gapoktan ini dibimbing oleh petugas penyuluh lapangan.

Gapoktan Sumber Anugerah memiliki 19 Poktan, dengan rincian Poktan dewasa sebanyak 13 Poktan, tiga KWT, dan tiga Kelompok Pemuda. Kegiatan operasional gapoktan ini mencakup empat unit usaha. Unit kegiatan yang pertama pengolahan jeruk Citrus Van Sambas. Unit kedua berupa kios sarana produksi pertanian (Saprodi) yang bergerak di bidang penjualan pupuk, yang ketiga adalah unit koperasi usaha Sumber Anugerah, dan yang terakhir adalah unit usaha penggilingan padi.

Produk olahan jus buah adalah cairan yang jernih atau agak jernih diperoleh dari pengepresan buah-buahan yang telah matang dan masih segar. Menurut Standar Industri Indonesia (2009)Jus buah adalah cairan yang diperoleh dengan memeras buah baik disaring maupun tidak dan dimaksudkan untuk minuman segar yang langsung diminum, mempunyai karakter warna, dan citarasa buah yang sama dengan buah segarnya.

Minuman jus buah kemasan adalah minuman ringan yang dikemas dalam berbagai bentuk dengan citra rasa buah, baik yang berasal dari sari buah segar, konsentrat, maupun perasa (essence) buah dengan menambahkan gula dan bahan tambahan makanan yang diijinkan (Badan Standardisasi Nasional Indonesia). Buah yang digunakan sebagai sari buah harus matang dan mempunyai cita rasa yang menyenangkan dan banyak mengandung asam.

Jus jeruk Citrus Van Sambas merupakan produk hasil dari kerjasama Penelitian dan Pengembangan Badan Penelitian dan Pengembangan Pertanian dengan Pemerintah daerah Provinsi Kalimantan Barat dan juga Pemerintah Daerah Kabupaten Sambas. Teknologi pengolahan jeruk dan merk produk Citrus Van Sambas ini diserahkan kepada Gapoktan Sumber Anugerah untuk diproduksi secara komersil. Jus jeruk ini telah didaftarkan hak paten nya dengan No S002007 00110. Merk terdaftar dengan No 2007027334.

Selama ini teknologi produksi pengolahan jus jeruk masih tergolong sederhana. Artinya sebagian besar dalam proses produksi masih menggunakan tenaga manusia dan peralatan yang sederhana. Peralatan yang digunakan adalah pisau, juicer manual, Cup sealler semi otomatis.

Bahan baku yang digunakan untuk pengolahan jus adalah buah jeruk dengan ukuran $\mathrm{C}$ atau D. Hal ini karena untuk mengurangi biaya produksi. Buah jeruk ukuran $\mathrm{C}$ atau $D$ lebih murah harganya dibanding dengan jeruk ukuran AB. Selain itu, juga lebih dikarenakan jeruk dengan kualitas ini kurang diminati konsumen. Buah dengan kualitas $A$ dan B dipasarkan di luar daerah Sambas, yang tersisa hanya jeruk dengan ukuran C atau D. Buah inilah yang dimanfaatkan oleh Gapoktan untuk diolah lebih lanjut. 


\section{Analisis Nilai Tambah}

Analisis nilai tambah digunakan untuk mengetahui adanya nilai tambah yang terdapat pada satu kilogram jeruk segar yang sudah diolah menjadi minuman kemasan. Nilai tambah usaha pengolahan jus jeruk merupakan pengurangan antara harga barang jadi dengan biaya pengolahan dalam proses produksi. Biaya produksi ditentukan oleh biaya bahan baku, biaya penyusutan, biaya penunjang dan biaya tenaga kerja.

\section{Biaya bahan baku}

Bahan baku dalam proses pembuatan jus jeruk adalah buah jeruk siam segar. Jeruk yang digunakan dalam produksi minuman kemasan ini adalah jeruk kualitas $C$ dan $D$. Harga jeruk selama masa penelitian fluktuatif. Hal ini mempengaruhi biaya yang dikeluarkan dalam proses industri. Harga satu kilogram jeruk rata-rata sebesar Rp 2,198

Tiap satu kilogram buah jeruk segar jeruk menghasilkan rata-rata 13 kemasan. Harga per kemasan jus Rp 1.200. Dapat dihitung dari satu kilogram buah jeruk segar Rp 2.198 menghasilkan minuman kemasan seharga Rp 15.119. Terdapat selisih angka sebesar Rp 12.921 yang menunjukkan besarnya nilai satu kilogram buah jeruk yang sudah diolah menjadi minuman kemasan. Rata-rata satu kemasan minuman memerlukan biaya sebesar Rp 213 untuk bahan baku berupa buah jeruk segar.

\section{Biaya Penunjang}

Biaya penunjang berupa biaya pembelian gula, bahan kimia makanan seperti kalium sorbat, CMC, asam sitrat, vitamin C, pewarna makanan, pembelian kemasan cup dan pipet. Rata-rata biaya penunjang untuk satu minuman kemasan sebesar Rp 232.

\section{Biaya Penyusutan}

Besarnya nilai tambah dalam usaha pengolahan minuman kemasan ini ditentukan pula oleh besarnya biaya penyusutan. Bangunan dan alat-alat yang digunakan dalam proses produksi mengalami penyusutan dengan metode garis lurus. Bangunan yang digunakan merupakan bangunan permanen dengan umur ekonomis selama 30 tahun. Bangunan ini selain digunakan pada proses produksi jus jeruk, juga digunakan untuk kegiatan produksi yang lainnya. Selain produksi jus jeruk, bangunan ini juga sebagai tempat produksi keripik buah dan minyak atsiri kulit jeruk. Dalam analisis ini biaya bangunan dihitung secara proporsi dari total biaya bangunan.

Alat yang digunakan berupa kompor gas dan tabung gas, mesin cup sealer semi otomatis, pisau dan talenan, gelas ukur plastik, teko dan panci besar. Besarnya biaya penyusutan untuk tiap kali produksi per kemasan adalah Rp 685.

\section{Biaya Tenaga Kerja}

Besarnya nilai tambah selanjutnya dipengaruhi oleh biaya tenaga kerja. Dalam usaha pengolahan jeruk ini digunakan tenaga kerja yang berasal dari kelompok wanita tani yang ada di Gapoktan Sumber Anugerah. Dalam tiap kali proses produksi, rata-rata memerlukan tenaga kerja sebanyak 3 orang. Upah untuk tiap tenaga kerja sebesar Rp 10.000. Rata-rata biaya tenaga kerja per kemasan minuman adalah sebesar Rp 546.

Besarnya nilai tambah dalam usaha pengolahan minuman kemasan jeruk di tentukan oleh selisih antara biaya bahan baku yang berupa biaya bahan, biaya penyusutan, biaya penunjang dan biaya tenaga kerja dengan harga produk per kemasan. Harga produk per kemasan sebesar Rp 1.200 di kurang dengan penjumlahan dari biaya bahan baku yaitu sebesar Rp 1.676. Dari Tabel 1, nilai tambah yang didapat setelah jeruk diolah menjadi minuman kemasan adalah sebesar -Rp 476. 
Tabel 1. Analisis Nilai Tambah Pengolahan Minuman Kemasan Jeruk Siam Di Gapoktan Sumber Anugerah

\begin{tabular}{lc}
\hline \multicolumn{1}{c}{ Variabel } & Rp/Kemasan \\
\hline 1. Harga barang jadi & 1200 \\
2. Biaya Produksi & \\
a. Biaya bahan baku & 213 \\
b. biaya penunjang & 232 \\
c. biaya penyusutan peralatan & 685 \\
d. biaya TK & 546 \\
3. Biaya Produksi & 1,676 \\
4. Nilai Tambah & -476 \\
\hline
\end{tabular}

Sumber : Analisis data primer 2011

\section{Analisis Efisiensi}

Untuk mengetahui efisiensi faktor-faktor produksi dalam usaha pengolahan jeruk dapat digunakan fungsi produksi Cobb-Douglas. Fungsi Cobb-Douglas merupakan fungsi produksi yang menggunakan persamaan regresi. Dalam menetukan persamaan regresi digunakan alat bantu program Statistical Product and Service Solution (SPSS) versi 18.

Analisis Cobb-Douglas merupakan salah satu alat analisis statistik parametris. Data yang akan dianalisis dengan menggunakan statistik parametris harus memenuhi beberapa ketentuan. Salah satu syarat data tersebut haruslah berdistribusi normal (Sugiyono, 2007).

Data yang berdistribusi normal bisa dideteksi dengan menggunakan uji statistik deskriptif yaitu dengan melihat nilai skewness dan kurtosis. Data yang berdistribusi normal sebaran rasio skewness kurtosis nya berada diantara -2 dan 2 . Setelah dilakukan uji secara simultan diketahui variabel produksi (Y), bahan baku (X1), penunjang (X2) dan biaya tenaga kerja (X3) tidak berdistribusi normal dengan masing-masing rasio skewness kurtosis sebesar 4,04 dan 4,$07 ; 3,41$ dan 1,$98 ; 4,22$ dan 3,$57 ; 1,345$ dan 5,$85 ; 6,03$. Sedangkan untuk biaya Penyusutan, tidak dapat di analisis karena besarnya sama di tiap kali proses produksi.

Dilihat dari rasio nilai skewness dan kurtosis agar tercapai kriteria data yang berdistribusi normal maka perlu dikeluarkan data yang penyebarannya tidak normal, yaitu data proses produksi yang ke 2, 3 dan 4 . Hal ini dikarenakan data produksi yang ke 2, 3 dan 4 terlalu jauh simpangannya dari data proses produksi rata-rata.

Setelah dikeluarkan data yang berdistribusi tidak normal, maka didapatlah rasio skewness dan kurtosis untuk variabel produksi sebesar 0,71 dan -0,50. Biaya bahan baku sebesar 0,50 dan 1,63. Untuk biaya penyusutan sebesar $-0,70$ dan $-0,76$. Sedangkan untuk tenaga kerja rasio skewness dan kurtosisnya sebesar $-1,56$ dan $-1,7$. Dari keempat variabel yang di uji normalitas datanya, maka terpenuhi kriteria data yang berdistribusi normal, yaitu kisaran rasio skewness kurtosis berada diantara -2 dan +2 .

Setelah dilakukan analisis, maka variabel yang tersisa adalah variabel X1, X2 dan X3 yaitu variabel bahan baku, bahan penunjang dan tenaga kerja memenuhi syarat untuk bisa dilanjutkan kedalam persamaan fungsi Cobb-Douglas. Dengan demikian yang masuk ke dalam persamaan fungsi Cobb-Douglas hanya tinggal tiga variable bebas. Dari hasil analisis 
diketahui variabel X1, X2 dan X3 mempengaruhi $Y$ sebesar 95,8 \%. Hal ini berarti sebesar $95,8 \%$ variabel produksi ditentukan oleh besarnya bahan baku, biaya penunjang dan tenaga kerja yang digunakan, sisanya pengaruhi oleh faktor lain yaitu sebesar $4,2 \%$.

Tabel 2. Pengaruh besarnya biaya bahan baku, biaya penunjang, dan biaya tenaga kerja terhadap biaya produksi

\begin{tabular}{|ccccc|}
\hline Model & $\mathrm{R}$ & $\mathrm{R}$ Square & Adjusted R Square & Std. Error of the Estimate \\
\hline 1 & $.958^{\mathrm{a}}$ & .918 & .914 & 11.46768 \\
\hline
\end{tabular}

Koefisien regresi yang didapat setelah dilakukan analisis sebesar $-50,09$. Bentuk Fungsi Cobb Douglas pada usaha pengolahan jus jeruk Citrus Van Sambas dapat dituliskan sebagai berikut :

$$
Q=-50.09\left(-\mathrm{I}_{1}^{0,097}+\mathrm{I}_{3}{ }^{0,008}+\mathrm{I}_{4}^{0,156}\right)+\mathrm{e}
$$

Indeks efisiensi sebesar - 50,09 menunjukkan bahwa usaha pengolahan jus jeruk ini belum efisien karena bernilai lebih kecil dari satu. Dari persamaan diatas menunjukkan bahwa dalam proses produksi jus jeruk, variabel bahan baku belum efisien, sedangkan bahan penunjang dan biaya tenaga kerja sudah efisien.

Berdasarkan hasil diatas, maka hipotesis yang menyatakan bahwa variabel dalam usaha pengolahan jeruk siam sudah efisien ternyata ditolak. Variabel dalam usaha pengolahan jeruk siam ada yang sudah efisien yaitu variabel tenaga kerja dan variabel bahan penunjang, sedangkan untuk variabel bahan baku masih belum efisien.

Penggunaan biaya bahan baku berupa pembelian buah jeruk yang belum efisien disebabkan karena dalam penggunaan buah jeruk untuk tiap kali proses produksi tidak sama. Tidak efisiennya penggunaan bahan baku juga bisa disebabkan oleh fluktuasi harga jeruk. Pada musim panen raya, buah jeruk murah harganya, sehingga bisa menekan biaya produksi. Harga jeruk yang tinggi menyebabkan biaya produksi juga ikut tinggi. Padahal harga jus dijual tidak berubah pada musim panen maupun diluar musin panen.

Harga jual jus jeruk yang tidak memperhatikan batas minimal harga pokok penjualan juga merupakan penyebab usaha ini tidak efisien. Penentuan harga jual suatu barang harus memperhatikan besarnya biaya produksi. Untuk menutupi ketidakefisienan usaha ini dapat dilakukan dengan cara meningkatkan harga jual produk hingga diatas titik impas harga (BEP harga). Harga jual jus jeruk bisa menguntungkan jika berada diatas titik impas harga, yaitu diatas harga Rp 1.875 per kemasan. Penentuan harga jual jus Citrus Van Sambas sebesar Rp 1.200 per kemasan pada awalnya sebagai strategi pemasaran dalam memenangkan konsumen minuman kemasan. Hal ini untuk mengimbangi harga minuman kemasan lainnya. Jika dilihat dari kualitas produk minuman, jus Citrus Van Sambas memiliki kelebihan yaitu berasal dari sari buah jeruk asli. Berbeda dengan minuman kemasan jeruk lainnya yang hanya berupa perasa jeruk. Dengan demikian jus Citrus Van Sambas tidak bisa disejajarkan dengan minuman jeruk kemasan lainnya yang hanya merupakan minuman biasa yang ditambah perasa (essence) jeruk. Jus jeruk ini harus disejajarkan dengan produk yang berasal dari sari buah asli. Minuman yang berasal dari sari buah asli lebih tinggi harganya dibanding dengan minuman perasa jeruk biasa. 


\section{PENUTUP \\ Kesimpulan}

Berdasarkan hasil analisis yang telah diuraikan sebelumnya, maka dapat disimpulkan usaha pengolahan jeruk siam di Gapoktan Sumber Anugerah tidak memiliki nilai tambah. Dari hasil perhitungan didapat bahwa besarnya nilai tambah yaitu : -Rp 476. Dari tiga variabel dalam usaha pengolahan jeruk siam yaitu biaya bahan baku buah jeruk, biaya penunjang dan biaya tenaga kerja, didapat koefisien efisiensi sebesar -50,09 yang berarti usaha pengolahan jeruk ini belum efisien. Usaha pengolahan jeruk siam ini masih belum memberikan nilai tambah kepada petani secara ekonomis, tetapi secara non ekonomi (sosial), usaha ini memberikan nilai tambah.

\section{Saran}

Agar tercapai nilai tambah dari usaha pengolahan jus jeruk sebaiknya ditiap proses produksi diperbanyak volume produksi. Sebaiknya dalam penentuan harga jual produk, memperhatikan besarnya biaya produksi, yaitu diatas harga $\mathrm{Rp} 1.875 .-$

\section{DAFTAR PUSTAKA}

Badan Penelitian dan Pengembangan Pertanian, Departemen Pertanian. 2005. Prospek dan Arah Pengembangan Agribisnis. Bogor

Bangun , W. 2007. Teori Ekonomi Mikro. Refika Aditama. Bandung

Badan Pusat Statistik Provinsi Kalimantan Barat. 2008.Kalimantan Barat Dalam Angka 2008. Pontianak

Dinas Koperasi, UMKM, Perindustrian dan Perdagangan Kabupaten Sambas. 2009. Laporan Kegiatan Monitoring \& Evaluasi Perkembangan Industri di Kab. Sambas. Sambas

Ermawati, T. 2000. Analisis Nilai Tambah, Efisiensi dan Saluran Pemasaran Agroindustri Emping Melinjo di Kecamatanamatan Udanawu Kabupaten Blitar. Malang(http://skripsi.umm.ac.id) didownload 12 Januari 2011 pukul 22.51 WIB. Tidak dipublikasikan

SNI.2009. Badan Standardisasi Nasional Indonesia. Jakarta

Sugiyono. 2007. Metode Penelitian Bisnis. Alfabeta. Bandung

Soekartawi, 1994. Teori Ekonomi Produksi Dengan Pokok Bahasan Analisis Fungsi Cobb-Douglas (Theory of Production Economics. RajaGrafindo Persada, Jakarta

Wardhani, M.R. 1999. Analisis Nilai Tambah Komoditi Melinjo Pada Agroindustri Emping Melinjo di Kab. Madiun. Tesis Program Pasca Sarjana. Universitas Brawijaya. Malang.Tidak dipublikasikan. 